\title{
Frasa Nominal Bahasa Nambla (Tukuih)
}

\section{(Noun Phrase in Nambla Language (Tukuih)}

\author{
Yohanis Sanjoko \\ Balai Bahasa Provinsi Papua dan Provinsi Papua Barat \\ Jalan Yoka, Waena, Distrik Heram, Kotamadya Jayapura, Papua \\ Ponsel: 081344528976 \\ Pos-el: triojoko55@yahoo.com
}

\begin{abstract}
This paper discusses about noun phrase in Nambla language (Tukuih). Noun phrase is a phrase which has same distribution as noun. The objective of this paper is to describe the patterns of noun phrase of Nambla language, kinds of word classes which fill into attribute constituent, word class sequences which fill into attribute constituent and correlation of meaning between nucleus constituent and attribute one. This paper uses descriptive method which includes collecting data, analyzing data and presenting the result of data analysis. In collecting the data, the researcher uses conversational method by stimulating technique as a basic technique and face to face conversation technique and noting technique as the advance technique. In analyzing the data, the researcher uses distributional method. General patterns of noun phrase of Nambla language is DM. Noun phrase of Nambla language consist of nucleus constituent which is always filled by noun and attribute constituent which can be filled by noun, pronoun, adjective, determiner, numeral, and relative clause. Some relations of meanings which emerge as a result of this syntax process are possessive meaning, locative, qualitative, quantitative, deictic and description.
\end{abstract}

Keywords: Nambla language, Noun phrase, constituent, nucleus, attribute

\begin{abstract}
Abstrak
Tulisan ini membahas frasa nominal dalam bahasa Nambla (Tukuih). Frasa nominal adalah frasa yang memiliki distribusi yang sama dengan kata nominal. Tujuan tulisan ini adalah untuk mendeskripsikan pola frasa nominal bahasa Nambla, jenis-jenis kelas kata pengisi konstituen atribut, urutan kelas kata pengisi konstituen atribut, dan hubungan makna antara konstituen inti dengan konstituen atribut. Tulisan ini mengunakan metode deskriptif dengan tiga tahapan, yaitu tahap penyediaan data, tahap analisis data, dan tahap penyajian hasil analisis data. Penyediaan data tulisan ini menggunakan metode cakap dengan teknik pancing sebagai teknik dasar dan teknik cakap semuka serta teknik catat sebagai teknik lanjutan. Analisis data menggunakan metode distribusional. Pola umum frasa nominal bahasa Nambla adalah DM. Frasa nominal bahasa Nambla terdiri dari konstituen inti yang selalu diisi oleh nomina dan konstituen atribut yang dapat diisi oleh nomina, pronomina, adjektif, artikel penentu, numeralia, dan klausa relatif. Beberapa hubungan makna yang timbul sebagai akibat proses sintaksis ini, yaitu menyatakan makna posesif, lokatif, kualitatif, kuantitatif, deiktis, dan deskripsi.
\end{abstract}

Kata kunci: bahasa Nambla, Frasa nominal, konstituen, inti, atribut 


\section{Pendahuluan}

Nominal merupakan salah satu kelas utama di dalam semua bahasa di dunia. Karena pentingnya nomina di dalam suatu bahasa, ahli bahasa di dunia selalu memasukkan nomina dalam pembicaraan tentang kelas kata. Termasuk dalam bagian pembicaraan nomina adalah pembicaraan tentang frasa nominal karena frasa ini mempunyai nomina sebagaikonstituen intinya.

Penelitian ini membicarakan tentang frasa nominal bahasa Nambla (Tukuih), sebuah bahasa daerah yang digunakan oleh suku Tukuih yang tinggal di Kampung Nambla, Distrik Senggi, Kabupaten Keerom, Provinsi Papua. Penutur bahasa Nambla diperkirakan 60-an orang. Bahasa Nambla merupakan temuan Tim Pemetaan Bahasa-Bahasa Daerah di Provinsi Papua dan Provinsi Papua Barat pada tahun 2009. Di dalam penelitian ini dibahas mengenai pola frasa nominal bahasa Nambla, jenis-jenis kelas kata pengisi konstituen atribut, urutan kelas kata pengisi konstituen atribut, dan hubungan makna antara konstituen inti dengan konstituen atribut.

\section{Landasan Teori}

Penelitian ini menggunakan teori sintaksis. Secara sistematis sintaksis dapat dibagi menjadi tiga tataran, yaitu fungsi, kategori, dan peran (Sudaryanto, 1983: 13, Verhaar, 1989: 70). Fungsi sintaksis adalah tataran yang pertama, tertinggi, dan paling abstrak. Fungsi sintaksis bersifat formal, artinya fungsi sintaksis merupakan tempat kosong. Fungsi itu memiliki "bentuk" tertentu, tetapi harus diisi oleh "bentuk" tertentu, yaitu suatu kategori. Fungsi itu juga tidak mempunyai "makna" tertentu tetapi diisi oleh "makna" tertentu, yaitu peran. Setiap fungsi adalah tempat kosong yang harus diisi oleh dua pengisi, yaitu kategori (menurut bentuk) dan pengisi semantis (menurut peran) (Verhaar, 1989: 72). Keformalan fungsi sintaksis juga dalam arti bahwa fungsi itu pada hakikatnya berhubungan dengan fungsi lain, tanpa hubungan tersebut fungsi tidak ada sama sekali. Keformalan fungsi sintaksis mencakup dua ciri, yaitu kekosongan dan relasionalitas (Verhaar, 1989: 78).

Kategori sintaksis adalah tataran kedua dengan tingkat keabstrakan yang lebih rendah daripada fungsi sintaksis (Sudaryanto, 1983: 13). Kategori tidak bersifat relasional, hubungan antar kategori bersifat sistemik. Pengetahuan tentang nomina dalam suatu tuturan, misalnya, tidak harus dihubungkan dengan verba, adjektiva, numeralia, dan begitu sebaliknya (Verhaar, 1989: 83-87).

Peran sintaksis adalah tataran yang ketiga dan terendah tingkat keabstrakannya jika dibandingkan dengan kedua yang lainnya. Peran sintaksis bersifat relasional (Sudaryanto, 1983: 13).

Ketiga konsep sintaksis tersebut tidak hanya beroperasi pada tataran sintaksis klausa tetapi juga beroperasi pada tataran sintaksis frasa. Pembagian lebih saksama mengenai ketiga konsep di atas akan sampai pada konsep yang dilabeli dengan istilah "bawahan" dan "atasan" sehingga ada fungsi, kategori, peran "atasan" di satu pihak dan ada fungsi, kategori, peran "bawahan" di pihak lain (Sudaryanto, 1983: 14).

Relasionalitas fungsi sintaksis mengimplikasikan adanya keberuntunan susunan konstituen sintaksis. Konstituen yang bersangkutan diurutkan dalam proses peruntunan dan membentuk susunan beruntun yang seterusnya dalambahasa tertentu membentuk pola tertentu. Mengenai urutan konstituen ini Alisyahbana (1975: 59) mengemukakan apa yang disebutnya 'hukumD-M". Menurutnya susunan kata bahasa Indonesia mempunyai aturan, yaitu baik dalam kata majemuk maupun dalam kalimat segala sesuatu yang menerangkan selalu terletak di belakang yang diterangkan. Kekecualian "hukum D-M" terdapat pada beberapa golongan kata, meskipun menerangkan sesuatu senantiasa/sering di depan kata yang diterangkan. Beberapa kata tersebut adalah kata bantu, kata keterangan, dan kata depan (Alisyahbana, 1975: 59 60). Susunan beruntun baik yang klausal maupun frasal mentaaati "hukum D-M" dalam apa yang disebut keselarasan infraklausal, artinya hukum tersebut berlaku untuk klausal maupun frasa. Menurut Greenberg (via Verhaar, 1989: 263) “hukumD-M” berlaku umum untuk bahasa yang berurutan VO, sedangkan untuk bahasa OV berlaku "hukum M-D".

Verhaar (1996: 291) mendefinisikan frasa sebagai kelompok kata yang merupakan bagian fungsional dari tuturan yang lebih panjang. Frasa sebagai bagian fungsional dalam arti tadi adalah fungsional 
justru dalam struktur ekstrafrasalnya, yaitu frasa sejauh frasa itu merupakan konstituen di dalam konstituen yang lebih menyeluruh. Di samping struktur ekstrafrasal tersebut ada pula struktur intrafrasalnya. Struktur intrafrasal itulah yang justru menentukan tipe frasa, misalnya frasa nominal memiliki nominal sebagai konstituen induk dan atribut sebagai konstituen bawahan (Verhaar, 1996: 292).

Penelitian ini menggunakana tiga tahapan strategis yang dilakukan secara beruntun. Ketiga tahapan tersebut adalah tahap penyediaan data, tahap penganalisisan data, dan tahap penyajian hasil analisis data (Sudaryanto, 1993: 5).

Penyediaan data penelitian ini menggunakan metode cakap dengan teknik pancing sebagai teknik dasar dan teknik cakap semuka serta teknik catat sebagai teknik lanjutan(Sudaryanto, 1993: 137-139). Sementara itu, analisis data menggunakan metode distribusional dengan teknik bagi unsur langsung sebagai teknik dasar dan teknik lesap, teknik pindah, dan teknik sisip sebagai teknik lanjutan (Sudaryanto, 1993: 31 - 71). Setelah data dianalisis hasilnya disajikan dengan metode formal (Sudaryanto, 1993:145).

\section{Pola Frasa Nominal Bahasa Nambla (Tukuih)}

Suatu nomina dalam bahasa Nambla dapat diperluas ke arah kanan atau ke arah kiri. Perluasan ini dilakukan dengan menjajarkan sebuah kata tertentu di letak kanan atau letak kiri nomina tertentu. Berdasarkan penelitian terhadap kategoripengisinya diperoleh pola frasa nominal sebagai berikut.

\subsection{Pola $\mathbf{N}+\mathrm{N}$}

Suatu nomina dalam bahasa Nambla dapat diperluas ke arah kiri. Perluasan ini dilakukan dengan menjajarkan sebuah nomina di letak kiri nomina tertentu. Suatu nomina yang berada di letak kanan berstatus sebagai konstituen inti, sedang nomina yang berada di letak kiri berstatus sebagai atribut.

Contoh:

$$
\begin{array}{ll}
\text { (1) misi pke } \\
\text { atr inti } \\
\text { 'pisang' 'pohon' } \\
\text { (pohon pisang) }
\end{array}
$$

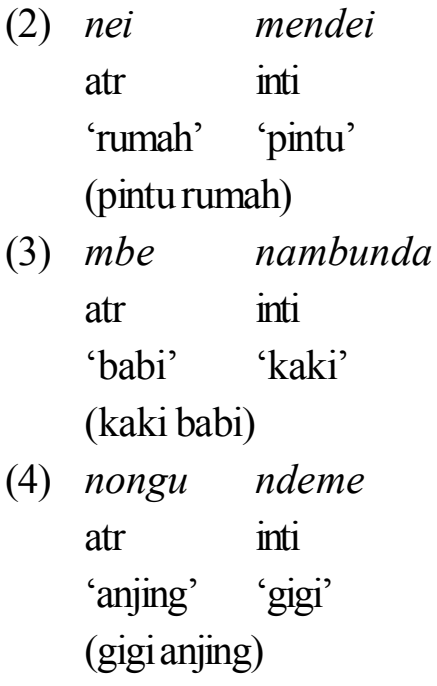

\subsection{Pola N + Art}

Suatu nomina dalam bahasa Nambla dapat diperluas ke arah kanan. Perluasan ini dilakukan dengan menjajarkan sebuah artikel penentu di letak kanan nomina tertentu. Suatu nomina yang berada di letak kiri berstatus sebagai konstituen inti, sedang artikel penentu yang berada di letak kanan berstatus sebagai atribut. Contoh:

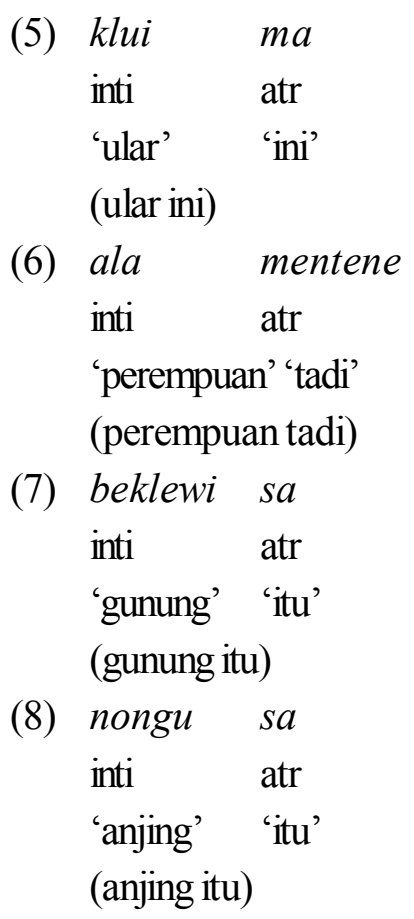

\subsection{Pola N + N + Art}

Suatu nomina dalambahasa Nambla dapat diperluas ke arah kiri dan sekaligus ke arah kanan. Perluasan ini dilakukan dengan menjajarkan sebuah nomina di letak kiri nomina tertentu dan menjajarkan artikel 
tertentu di letak kanan. Suatu nomina yang berada di letak kanan berstatus sebagai konstituen inti, sedang nomina yang berada di letak kiri berstatus sebagai atribut, dan artikel yang berada di letak kanan sebagai atribut.

Contoh:

(9) $l i$

$\begin{array}{lll}l i & \text { nam } & \text { sa } \\ \text { atr } & \text { inti } & \text { atr }\end{array}$

'mata' 'bulu' 'itu'

(bulu mata itu)

(10) kembla namme ma

atr inti atr

'kepala' 'rambut' 'ini'

(rambut kepala ini)

(11) $l i \quad$ je jigembe

atr inti atr

'mata' 'biji' 'tersebut'

(biji mata tersebut)

(12) ndime meni ma

atr inti atr

'hidung' 'lubang' 'ini'

(lubang hidung ini)

\subsection{Pola N + N + PrP}

Suatu nomina dalam bahasa Nambla dapat diperluas ke arah kiri dan sekaligus ke arah kanan. Perluasan ini dilakukan dengan menjajarkan sebuah nomina di letak kiri nomina tertentu, dan menjajarkan pronomina persona di letak kanan. Suatu nomina yang berada di letak kanan berstatus sebagaikonstituen inti, sedang nomina yang berada di letak kiri berstatus sebagai atribut. Sementara itu, pronomina yang berada di letak kanan sebagai atribut.

Contoh:

$\begin{array}{cll}\text { (13) nongu } & \text { moko } & \text { sae } \\ \text { atr } & \text { inti } & \text { atr } \\ \text { 'anjing' 'anak' } & \text { 'dia' } \\ \text { (anak anjing dia) } & \\ \text { (14) kelapa bake } & \text { jumo } \\ \text { atr } & \text { inti } & \text { atr } \\ \text { 'kelapa' 'pohon' } & \text { 'kamu' } \\ \text { (pohon kelapa kamu) } & \end{array}$

Gramatika, Volume I, Nomor 2, Juli-Desember 2013

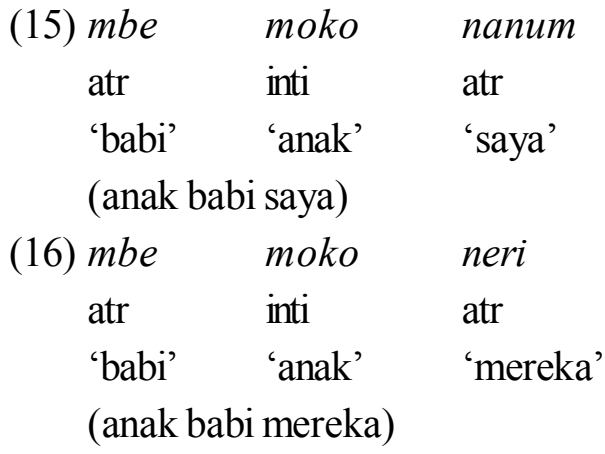

\subsection{Pola N + N + PrP + Art}

Suatu nomina dalam bahasa Nambla dapat diperluas ke arah kiri dan ke arah kanan sekaligus. Perluasan ini dilakukan dengan menjajarkan sebuah nomina di letak kiri nomina tertentu, menjajarkan pronomina persona di letak kanan, dan menjajarkan artikel tertentu di letak paling kanan. Suatu nomina yang berada di letak kanan berstatus sebagai konstituen inti, sedang nomina yang berada di letak kiri berstatus sebagai atribut. Sementara itu, pronomina persona dan artikel yang berada di letak kanan sebagai atribut. Contoh:

(17)

$\begin{array}{llll}\text { nongu } & \text { moko } & \text { nanum } & \text { ma } \\ \text { atr } & \text { inti } & \text { atr } & \text { atr } \\ \text { 'anjing' 'anak' } & \text { 'milik saya' 'ini' } \\ \text { (anak anjing saya ini) } & \end{array}$

(18) nei mendei yumo ma atr inti atr atr 'rumah' 'pintu' 'milik kamu' 'ini' (pintu rumah kamu ini)

(19) nongu ndeme neri ma atr inti atr atr 'anjing' 'gigi' 'milik mereka' 'ini' (gigi anjing mereka ini)

(20) mbe nambunda nanum sa atr inti atr atr 'babi' 'kaki' 'milik saya' 'itu' (kaki babi saya itu)

\subsection{Pola N + PrP + Adj}

Suatu nomina dalam bahasa Nambla dapat diperjelas ke arah kanan. Perluasan ini dilakukan dengan menjajarkan sebuah pronomina persona di letak kanan nomina tertentu dan diikuti adjektif. Suatu nomina 
yang berada di letak paling kiri berstatus sebagai konstituen inti, sedang pronomina persona dan adjektif yang berada di letak kanan berstatus sebagai atribut.

Contoh:

\begin{tabular}{|c|c|c|c|}
\hline (21) & $n e i$ & nanum & liki \\
\hline & inti & atr & atr \\
\hline & $\begin{array}{l}\text { 'rumah' } \\
\text { (rumah b }\end{array}$ & $\begin{array}{l}\text { 'milik saya' } \\
\text { ru saya) }\end{array}$ & 'baru' \\
\hline (22) & $n e i$ & maninam & api \\
\hline & inti & atr & atr \\
\hline & $\begin{array}{l}\text { 'rumah' } \\
\text { (rumah b }\end{array}$ & $\begin{array}{l}\text { 'milik kami' } \\
\text { sar kami) }\end{array}$ & 'besar' \\
\hline (23) & $n e i$ & neri & liki \\
\hline & inti & atr & atr \\
\hline & $\begin{array}{l}\text { 'rumah' } \\
\text { (rumah b }\end{array}$ & $\begin{array}{l}\text { nilik mereka' } \\
\text { ru mereka) }\end{array}$ & 'baru' \\
\hline (24) & $n e i$ & neri & moru \\
\hline & inti & atr & atr \\
\hline & $\begin{array}{l}\text { 'rumah' } \\
\text { (rumahb }\end{array}$ & $\begin{array}{l}\text { milik mereka' } \\
\text { gus mereka) }\end{array}$ & 'bagus' \\
\hline
\end{tabular}

\subsection{Pola N + Adj}

Suatu nomina dalam bahasa Nambla dapat diperluas ke arah kanan. Perluasan ini dilakukan dengan menjajarkan sebuah adjektif di letak kanan nomina tertentu. Suatu nomina yang berada di letak kiri berstatus sebagai konstituen inti, sedang adjektif yang berada di letak kanan berstatus sebagai atribut.

Contoh:

$$
\begin{aligned}
& \text { (25) knipa wi } \\
& \text { inti atr } \\
& \text { 'parang' 'tajam' } \\
& \text { (parang tajam) }
\end{aligned}
$$

(26) $m b e \quad a p i$

inti atr

'babi' 'besar'

(babi besar)

(27) nombuk mo

inti atr

'manik-manik' 'merah'

(manik-manik merah)

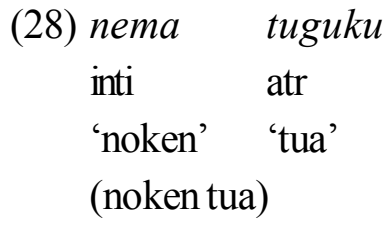

\subsection{Pola N + Adj + Art}

Suatu nomina dalambahasa Nambla dapat diperluas ke arah kanan. Perluasan ini dilakukan dengan menjajarkan sebuah adjektifdan sebuah artikel penentu di letak kanan nomina tertentu. Suatu nomina yang berada di letak kiri berstatus sebagai konstituen inti, sedang adjketif dan artikel penentu yang berada diletak kanan berstatus sebagai atribut.

Contoh:

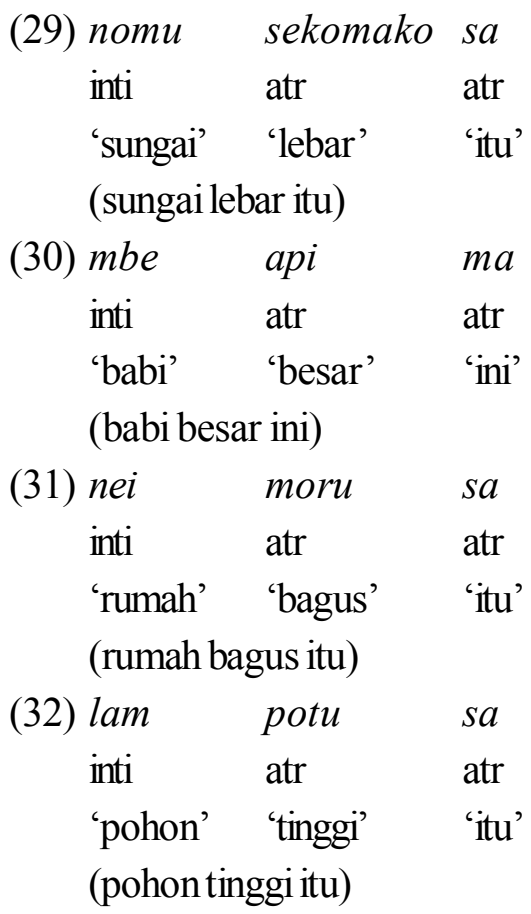

\subsection{Pola $\mathbf{N}+\mathbf{N u m} / \mathbf{N}+$ Penggolong + Num}

Suatu nomina dalam bahasa Nambla dapat diperluas ke arah kanan. Perluasan ini dilakukan dengan menjajarkan sebuah numeralia di letak kanan nomina tertentu. Suatu nomina yang berada di letak kiri berstatus sebagai konstituen inti, sedang numeralia yang berada di letak kanan berstatus sebagai atribut. Apabila terdapat penggolong sebagai atribut, maka penggolong tersebut berada tepat di letak kanan nomina dan berada sebelum numeralia. 
Contoh:

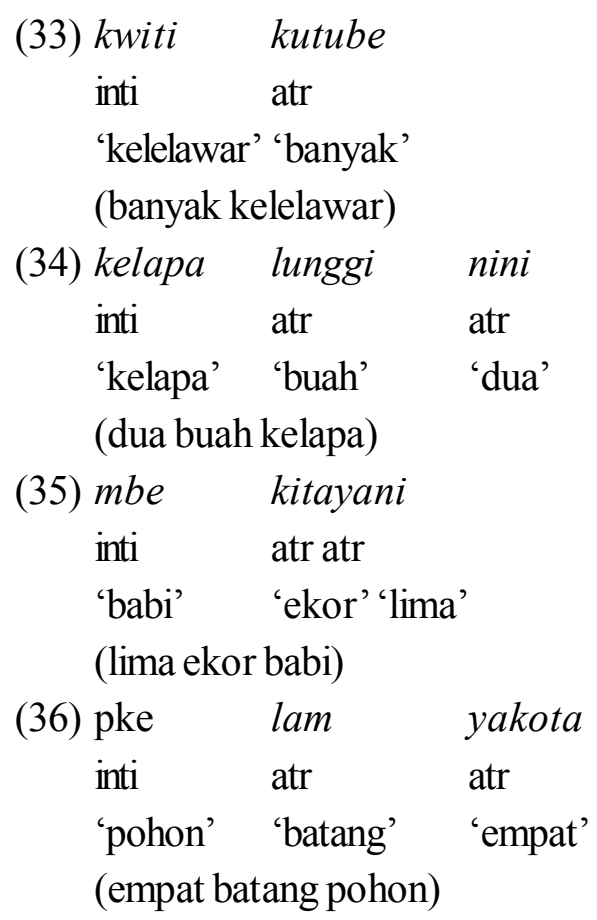

\subsection{Pola N + Klausa relatif}

Suatu nomina dalam bahasa Nambla dapat diperluas ke arah kanan. Perluasan ini dilakukan dengan menjajarkan sebuah klausa relatif di letak kanan nomina tertentu. Suatu nomina yang berada di letak kiriberstatus sebagai konstituen inti, sedang klausa relatif yang berada di letak kanan berstatus sebagai atribut.

Contoh:

$$
\begin{aligned}
& \text { (37) pke salipotu } \\
& \text { inti } \quad \text { atr } \\
& \text { 'pohon' 'yang' 'tinggi' } \\
& \text { (pohon yang tinggi) } \\
& \text { (38) nom } \quad \text { salinonggoima } \\
& \text { inti } \quad \text { atr } \\
& \text { 'sungai' 'yang' 'kering' } \\
& \text { (sungai yang kering) } \\
& \text { (39) mla } \quad \text { sali yemako } \\
& \text { inti atr } \\
& \text { 'anak' 'yang' 'pertama' } \\
& \text { (anak yang sulung) } \\
& \text { (40) pkesali lekendiae/lekesuguge } \\
& \text { inti atr } \\
& \text { 'pohon' 'yang' 'ditebang' } \\
& \text { (pohon yang ditebang) }
\end{aligned}
$$

Gramatika, Volume I, Nomor 2, Juli-Desember 2013

\section{Hubungan Makna antar Konstituen}

Pertemuan antar konstituen dalam suatu farasa menimbulkan hubungan makna, misalnya pertemuan kata nanum 'saya' dan mla 'anak' dalam frasa nanum mla 'anak saya' menimbulkan hubungan makna posesif. Dari penelitian terhadap hubungan makna antar konstituen dalam frasa nomina bahasa Nambla diperoleh hubungan makna sebagai berikut.

\subsection{Posesif}

Pada konstruksi ini, konstituen induk merupakan termilik bagi konstituen atribut yang menjadi pemiliknya.

Contoh:

(41) nanum mla
'saya' 'anak'
anak saya
(42) nanum lanemolu
'saya' 'suami'
suami saya
(43) neri nei
'mereka' 'rumah'
rumah mereka
(44) nggum nei
'atap' 'rumah'
atap rumah

\subsection{Lokatif}

Pada konstruksi ini, konstituen induk merupakan apa yang diasalkan bagi konstruksi atribut yang menjadi tempat asal.

Contoh:

$$
\begin{aligned}
& \text { (45) kinome nomokla } \\
& \text { 'laut' 'ikan' } \\
& \text { ikanlaut } \\
& \text { (46) jokokua anambla } \\
& \text { 'gadis' 'nambla' } \\
& \text { gadis Nambla } \\
& \text { (47) pentum la } \\
& \text { 'Papua' 'orang' } \\
& \text { orang Papua }
\end{aligned}
$$


(48) bekle la

'gunung' 'orang'

orang gunung

\subsection{Kualitatif}

Pada konstruksi ini, konstituen induk merupakan hal yang disifati oleh konstituen atribut yang menjadi penyifatnya.

Contoh:

(49) nombuk dum

'manik-manik' 'hitam'

manik-manik hitam

(50) $n e i$

'rumah' 'bagus'

rumah bagus

(51) nongu jokolu

'anjing' 'buas'

anjing buas

(52) mbe nongonta

'babi' 'liar'

babi liar

\subsection{Kuantitaf}

Pada konstruksi ini, konstituen induk merupakan hal yang diidentifikasikan derajat atau himpunannya oleh konstituen atribut yang menjadi penunjuk derajatnya. Contoh:
(53) tegi kutube
'nyamuk' 'banyak'
banyak nyamuk
(54) atu mudunda
'burung' 'satu ekor' seekor nyamuk
(55) kelapa lunggi nini 'kelapa' 'buah' 'dua' dua buah kelapa
(56) kai mubokolam 'pinang' 'satu tumpuk' setumpuk pinang

\subsection{Diektis}

Pada konstruksi ini, konstituen induk merupakan hal yang ditunjuk oleh konstituen atribut yang menjadi penunjuk/penentu.

Contoh:

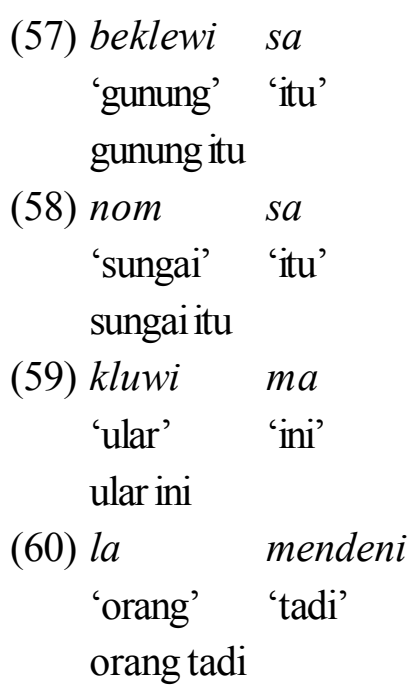

\subsection{Deskripsi}

Pada konstruksi ini, konstituen induk merupakan hal yang diperikan oleh konstituen atribut yang menjadi pemerinya.

Contoh:

$$
\begin{aligned}
& \text { (61) pke potu } \\
& \text { 'pohon' 'tinggi' } \\
& \text { pohon (yang) tinggi } \\
& \text { (62) nom nonggoima ko } \\
& \text { 'sungai' 'kering' 'sudah' } \\
& \text { sungai (yang) sudah kering } \\
& \text { (63) mla jumodinaskam kali } \\
& \text { 'anak' 'kamu' 'kecil' 'paling' } \\
& \text { anak kamu (yang) bungsu } \\
& \text { (64) apa pke lekendiae/lekesuguge } \\
& \text { 'ayah' 'pohon' 'ditebang' } \\
& \text { pohon (yang) ditebang ayah }
\end{aligned}
$$
(63) mla jumodinaskam kali
'anak' 'kamu' 'kecil' 'paling'
anak kamu (yang) bungsu
(64) apa pke lekendiae/lekesuguge 'ayah' 'pohon' 'ditebang' pohon (yang) ditebang ayah

\section{Simpulan}

Pola umum frasa nominal bahasa Nambla adalah DM, artinya konstituen atribut berada di letak kanan konstituen inti. Akan tetapi, apabila konstituen atribut berupa nomina maka konstituen atribut berada di letak kiri konstituen inti. Frasa nominal bahasa 
Nambla terdiri dari konstituen inti yang selalu diisi oleh nomina dan konstituen atribut yang dapat diisi oleh nomina, pronomina, adjektif, artikel penentu, numeralia, dan klausa relatif.

Sebuah nomina yang menduduki konstituen inti dapat diperluas dengan beberapa konstituen penjelas. Apabila konstituen penjelasnya lebih dari satu makna kemungkinan urutan konstituen penjelasnya adalah nomina (atr) + nomina (inti) + artikel penentu (atr), nomina (atr) + nomina (inti) + pronomina persona (atr), nomina (atr) + nomina (inti) + pronomina persona (atr) + artikel penentu (atr), nomina (inti) + adjektif (atr) + artikel penentu (atr), atau nomina (inti) + penggolong (atr) + numeralia (atr).

Beberapa hubungan makna yang timbul sebagai akibat proses sintaksis ini, yaitu menyatakan makna posesif, lokatif, kualitatif, kuantitatif, diektis, dan deskripsi.

\section{Daftar Pustaka}

Alisyahbana, Sutan Takdir. 1975. Tata Bahasa Indonesia. Jakarta: Dian Rakyat.

Sudaryanto. 1983. Keselarasan Predikat-Objek dalam Bahasa Indonesia. Jakarta: ILDEP. 1993. Metode dan Aneka Teknik Analisis Bahasa: Pengantar Penelitian Wahana Kebudayaan Secara Linguistis. Yogyakarta: Duta Wacana University Press.

Verhaar, J.W.M. 1989. Pengantar Linguistik Umum. Yogyakarta: Gadjah Mada University Press.

1996. Asas-Asas Linguistik Umum. Yogyakarta: Gadjah Mada University Press. 